\title{
miR-185 inhibits cell migration and invasion of hepatocellular carcinoma through CDC42
}

\author{
QINGJUN ZHANG ${ }^{1}$, YUN CHEN ${ }^{2}$ and KE LIU ${ }^{1}$ \\ ${ }^{1}$ Department of Hepatobiliary Surgery and ${ }^{2}$ Central Sterile Supply Department, \\ Central Hospital of Zibo, Zibo, Shandong 255000, P.R. China \\ Received November 30, 2017; Accepted May 17, 2018
}

DOI: 10.3892/ol.2018.8971

\begin{abstract}
Hepatocellular carcinoma (HCC) is a primary liver cancer with high incidence and mortality. miR-185, a microRNA with appriximately 22-28 nucleotides, was reported to be involved in many cancers. The potential mechanism of miR-185 on HCC through cell division cycle 42 (CDC42) was investigated. RT-qPCR was used to measure the RNA level of miR-185 and CDC42 in HCC tissues and cells. The dual luciferase reporter assay was used to verify whether CDC42 was a target gene for miR-185. Transwell assay was employed to detect the ability of migration and invasion to change miR-185. miR-185 expression was low in HCC and negatively correlated with CDC42. miR-185 inhibited HCC migration, invasion and miR-185 low expression predicted poor prognosis. CDC42 was predicted to be a target gene for miR-185, and regulated by miR-185. miR-185 suspressed the ability of cell migration and invasion through CDC42 in HCC. In conclusion, miR-185 suspressed migration and invasion of HCC cells by directly targeting CDC42. It is suggested that miR-185/CDC42 axis may present a novel target for HCC treatment.
\end{abstract}

\section{Introduction}

Primary liver cancer is a malignant tumor, incidence rate was the fifth and the mortality ranked third in 2007, and approximately $85-90 \%$ was hepatocellular carcinoma (HCC). Sub-Saharan Africa and Eastern Asia are the two most common places for $\mathrm{HCC}$, of which the incidence in China was more than half of the whole world (1). Metastasis and recurrence ofter occur in HCC due to factors, such as geographical location, race, sex, environment, and molecular factors. Therefore, identification of tumor biomarkers for early diagnosis is essential for HCC patients.

Correspondence to: Dr Qingjun Zhang, Department of Hepatobiliary Surgery, Central Hospital of Zibo, 54 Zibo Youth League Road, Zibo, Shandong 255000, P.R. China

E-mail: xgwz551365@126.com

Key words: hepatocellular carcinoma, miR-185, CDC42, migration, invasion
MicroRNAs (miRNAs), a class of small regulatory RNA molecules with $\sim 22-28$ nucleotides, inhibit target gene expression in post-transcriptional regulation by targeting the 3'UTR of mRNAs or cleaving their mRNA directly in order to inhibit protein expression (2-5). miR-185 was reported to play important roles in several human cancers, covering prostate carcinoma, lung cancer, ovarian, pediatric renal, breast, cervical and colon cancers (6-10). In prostate carcinoma cells, miR-185 downregulated androgen receptor (AR) to inhibit cell proliferation and induced apoptosis by directly targeting it (6). miR-185 also inhibited colorectal cell proliferation by targeting RhoA and CDC42 (11).

Cell division cycle 42 (CDC42) is a member of Rho GTPase family, which belong to subfamily of 20-30 kDa GTP-binding proteins of Ras superfamily (11-13). It was reported that CDC42 is overexpressed in various carcinomas, such as breast, colon, esophageal, bladder and liver cancer (14-17). CDC42 impacts cell cycle during cell division, leading to generation of multinucleated cells in primary mouse embryonic fibroblasts (18). Studies have found that the level in HCC tissues was higher than paracancerous tissues, and was connected with metastasis in HCC cells $(19,20)$.

In our study, the relationship between miR-185 and CDC42 and correlation in HCC was investigated. We analyzed the miR-185 expression level in HCC tissues and liver cancer cells with non-carcinomatous tissues and normal liver cells as control. The effects of overexpression or knockdown of miR-185 on migration and invasion of liver cancer cells HuH-7 was explored. Moreover, we examined the influence of miR-185 expression on CDC42 and the prognosis of patients. Finally, through recovery tests, we determined that miR-185 inhibits the cell processes by regulating CDC42 cell processes.

\section{Materials and methods}

Tissue samples and cell lines. Paired tumors and non-carcinomatous tissue were available from 63 patients with surgery from Central Hospital of Zibo. All the specimens were obtained with informed consent of the patients and the study was approved by the Ethics Committee of Central Hospital of Zibo (Zibo, China).

HuH-7 human hepatocellular carcinoma cell and the human normal hepatocyte L-02 cell line were purchased from American Type Culture Collection (ATCC; Manassas, VA, 
USA). Cells were incubated at constant temperature of $37^{\circ} \mathrm{C}$ with $5 \% \mathrm{CO}_{2}$.

Western blotting. For western blotting, the first cells were lysed using RIPA lysis buffer containing PMSF (both from Beyotime, Shanghai, China) on ice. Following centrifugation with $12,000 \mathrm{xg}$ at $4^{\circ} \mathrm{C}$, the concentration of protein was measured by $\mathrm{BCA}$ reagent kit (Solarbio, Beijing, China) and the absorbance was measured by a microplate reader. SDS-PAGE was applied for separation and transfer onto a PVDF membrane, and it was incubated at $4^{\circ} \mathrm{C}$ overnight with mouse anti-CDC42 monoclonal antibody (cat. no. ab41429; 1:1,000; Abcam, Cambridge, UK). After washing with TBST buffer (Tris-buffered saline with Tween-20, pH 8.0), the blots were incubated with anti-mouse IgG (1:3,000; cat. no. no. SAB4600004 Novus Biologicals, Littleton, $\mathrm{CO}, \mathrm{USA}$ ) at room temperature for $2 \mathrm{~h}$. The protein signal was detected with chemiluminescence using the Bio-Rad Gel Doc XR instrument (Bio-Rad Laboratories, Inc., Berkeley, CA, USA).

Transwell assay. Transwell assay was used to test the ability of migration and invasion. The Transwell chambers (Costar, Corning, NY, USA), were $8 \mu \mathrm{m}$ in size, with or without Matrigel (Clontech, Mountain View, CA, USA). The chambers within $200 \mu \mathrm{l}$ cell suspension was put into 24 -well plate containing $500 \mu \mathrm{l}$ medium. Culturing at $37^{\circ} \mathrm{C}$ with $5 \% \mathrm{CO}_{2}$ for about $48 \mathrm{~h}$ before the cells moved under the chambers. After fixed with methanol for $20 \mathrm{~min}$, the cells were stained using crystal violet and observed by microscope (BX51 Olympus, Shenzhen, China).

$R T-q P C R$. Total RNAs were extracted using TRIzol reagent (Invitrogen; Thermo Fisher Scientific, Inc., Carlsbad, CA, USA) and miRNAs using miRcute Extraction and Separation of miRNAs kit (Tiangen, Beijing, China). Reverse transcription of purified RNAs was used PrimeScript ${ }^{\mathrm{TM}}$ II 1st Strand cDNA Synthesis kit (Takara Biotechnology Co., Ltd., Dalian, China) conducted by two steps at $37^{\circ} \mathrm{C}$ for $5 \mathrm{~min}$ and $42^{\circ} \mathrm{C}$ for $25 \mathrm{~min}$ in $20 \mu \mathrm{l}$ reaction system. STEP ONE RT-qPCR Apparatus (Applied Biosystems, Foster City, CA, USA) and miRNA SYBR Green RT-qPCR kit (ABM, Inc., USA) were employed to perform the quantitative real time PCR. The following thermocycling conditions were used for PCR: 5 min at $95^{\circ} \mathrm{C}$, followed by 40 cycles of $95^{\circ} \mathrm{C}$ for $30 \mathrm{sec}$ and $65^{\circ} \mathrm{C}$ for $45 \mathrm{sec}$. GAPDH and U6 were used as normalization for CDC42 and miR-185, respectively. All the primers were purchased from Genechem (Shanghai, China), which were CDC42 forward: 5'-GCTCTAGAGCCCTTAAGGGGAG GAG-3' and reverse: 5'-GCTCTAGAAAAAATCCCTATTAA CAC-3'; U6 forward: 5'-CTCGCTTCGGCAGCACA-3' and reverse: 5'-AACGCTTCACGAATTTGCGT-3'; miR-185 forward: 5'-CAATGGAGAGAAAGGCAGTTCC-3' and reverse: 5'-AATCCATGAGAGATCCCTACCG-3'; GAPDH forward: 5'-GGTGAAGGTCGGAGTCAACG-3' and reverse: 5'-CAAAGTTGTCATGGATGHACC-3'.

Plasmid construction and luciferase reporter assay. TargetScan (www. targetscan.org), online software, predicted CDC42 was a target gene of miR-185 with binding site at 647-654 of its 3'UTR. In order to verify whether miR-185 interacts with $\mathrm{CDC} 42$, double luciferase reporter assay was performed. The 3'UTR oligonucleotide fragment of CDC42 was inserted into pcDNA3.1 plasmid vector (pcDNA3.1-CDC42-WT). Mutated the binding site from 5'-... UCUCUCC...-3' to 5'-...AGAGAGG...-3' and then inserted into pcDNA3.1 plasmid vector (pcDNA3.1-CDC42-MUT). The effectiveness of cloning was detected by sequencing.

HuH-7 cells at $80 \%$ confluence were seeded in 6-well plates and cultured overnight before transfection. miR-185 mimic or negative control (NC) and pcDNA3.1-CDC42-WT or pcDNA3.1-CDC42-MUT were co-transfected into HCC HuH-7 cells using Lipofectamine 3000 reagent (Invitrogen; Thermo Fisher Scientific, Inc.). Then the transfected cells were cultured at $37^{\circ} \mathrm{C}$ with $5 \% \mathrm{CO}_{2}$ for $48 \mathrm{~h}$ and harvested for analysis.

Transfection. The influence of miR-185 to cell migration and invasion, was investigated with $\mathrm{miR}-185 \mathrm{mimic}$ and inhibitor were used to overexpress or knock down miR-185. Similarly, we used small interfering RNA (siRNA) to interfere with the expression of CDC42, and detected the effect of miR-185 through CDC42 for cell migration and invasion.

HCC cells were seeded into a 6 -well plate and cultivated overnight to make sure that cells adhered to the wall. The medium was replaced before transfection, and the specific plasmids were transfected in HCC cells by Lipofectamine 3000 reagent (Invitrogen; Thermo Fisher Scientific, Inc.).

Statistical analysis. Experimental results were demonstrated using SPSS 20.0 software package (IBM Corp., Armonk, NY, USA). The differences between the groups were calculated using t-test or Dunnett's, Fisher's after one-way ANOVA test. In addition, $\chi^{2}$ test was used to compare the expression of miR-185 and the clinicopathological features of HCC patients. The Kaplan-Meier method with log-rank test was used to calculate the survival rates. A total of 63 cases of patients were divided into two groups [miR-185(+) and miR-185(-)] according to the miR-185 expression. The effects of the miR-185 expression on overall survival (OS) and disease-free survival (DFS) (in months) were analyzed using the multivariate Cox regression method. For all tests, $\mathrm{P}<0.05$ was considered to indicate a statistically significant difference.

\section{Results}

miR-185 expression is significantly low and correlates with CDC42 in HCC. miR-185 and CDC42 expression level of the 63 paired $\mathrm{HCC}$ and non-carcinomatous tissues was detected by RT-qPCR. For HCC tissues, the expression of miR-185 was reduced significantly compared with non-carcinomatous tissues $(\mathrm{P}<0.0001)$ (Fig. 1A). Similarly, miR-185 expression in HCC cells HuH-7 was decreased in contrast to normal HCC L-02 cells $(\mathrm{P}<0.0001)$, as shown in Fig. 1B. On the contrary, CDC42 was overexpressed in HCC cell lines HuH-7 vs. normal liver L-02 cells $(\mathrm{P}<0.0001)$ (Fig. 1C). miR-185 was correlated with CDC42 in HCC ( $r=-0.8049, \mathrm{P}<0.0001)$ (Fig. 1D).

miR-185 inhibits migration and invasion and miR-185 deficiency predictes poor prognosis of HCC patients. In order to test whether miR-185 influenced the progress of HCC, we used mimic or inhibitor to overexpress or knock down the expression of miR-185 in HuH-7 cells. The overexpression (P-value 
A

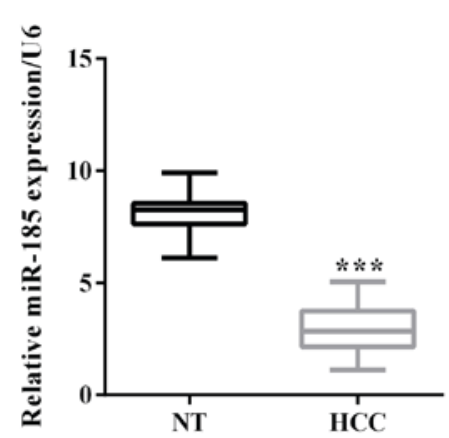

C

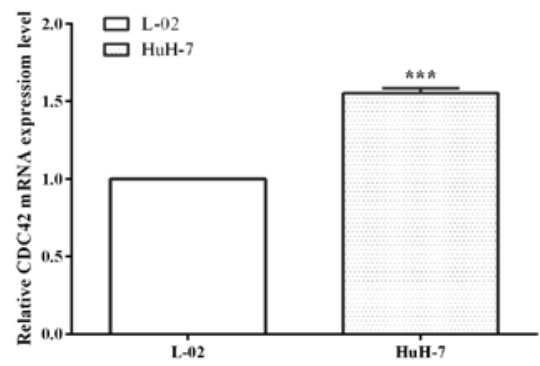

B

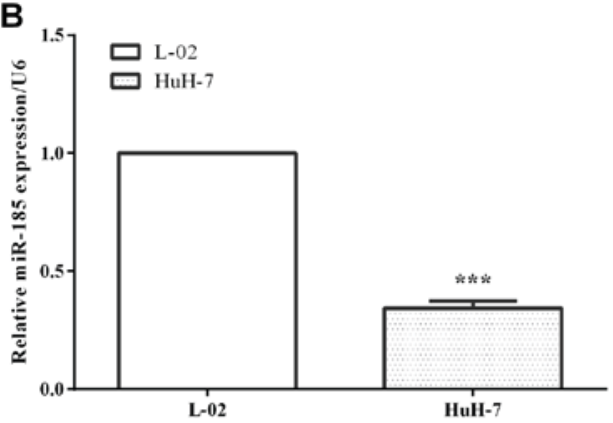

D

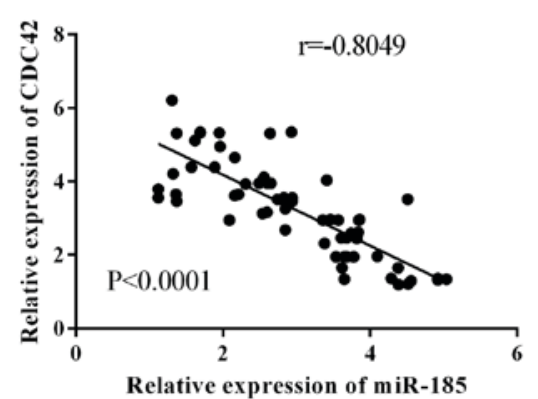

Figure 1. miR-185 expression is significantly low and correlates with CDC42 in HCC. (A) The relative expression level of miR-185 in HCC tissues and corresponding non-tumorous tissues. (B) miR-185 expression level in HCC cell lines HuH-7 and normal human HCC L-02 by RT-qPCR. (C) CDC42 mRNA level in HuH-7 was upregulated compared with CDC42 cells. (D) miR-185 expression is associated with CDC42 in HCC. ${ }^{* * *} \mathrm{P}<0.001$. CDC42, cell division cycle 42 ; HCC, hepatocellular carcinoma.

A

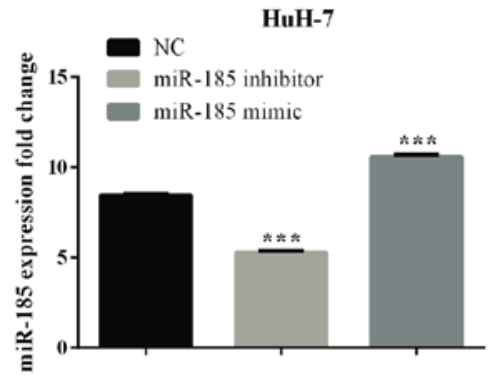

C
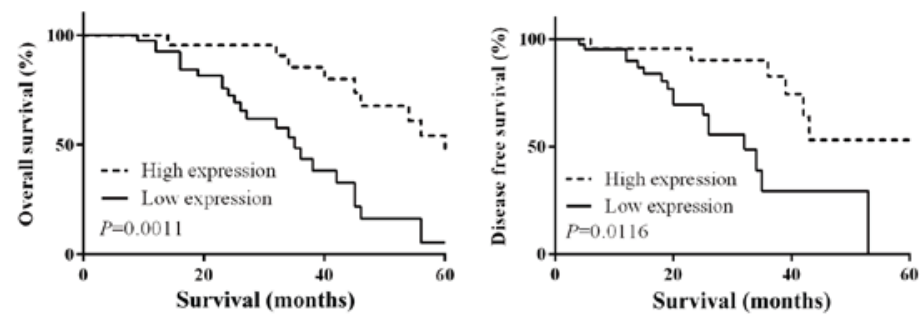

HuH-7

B
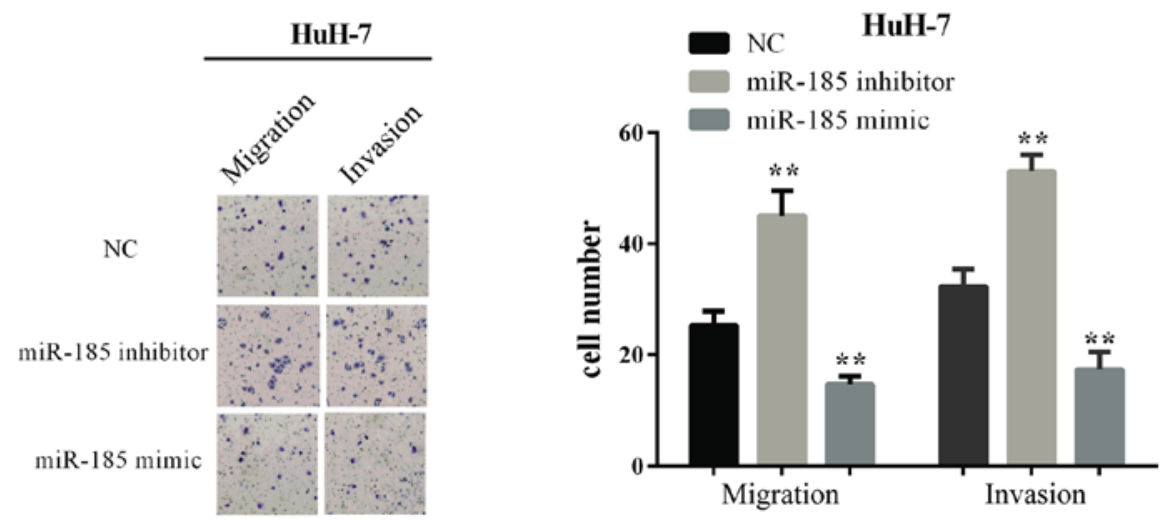

Figure 2. miR-185 inhibits migration and invasion and miR-185 deficiency predicted poor prognosis of HCC patients. (A) The effectiveness of the overexpressed and knockdown miR-185 in liver cancer cells HuH-7. (B) Transwell assay was used to analyze migration and invasion of HuH-7 cells. (C) The OS and DFS of patients with high $(\mathrm{n}=22)$ or low $(\mathrm{n}=41)$ miR-185 expression. ${ }^{* *} \mathrm{P}<0.01 ;{ }^{* * *} \mathrm{P}<0.001$. HCC, hepatocellular carcinoma; OS, overall survival; DFS, disease free survival.

was $<0.0001)$ or knockdown (P-value was <0.0001) effects are shown in Fig. 2A.
Transwell assay was used to detect the influence of miR-185 on migration and invasion. As shown in Fig. 2B, in knockdown 
A

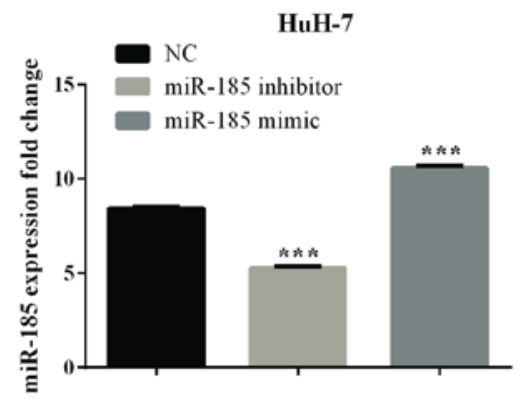

C
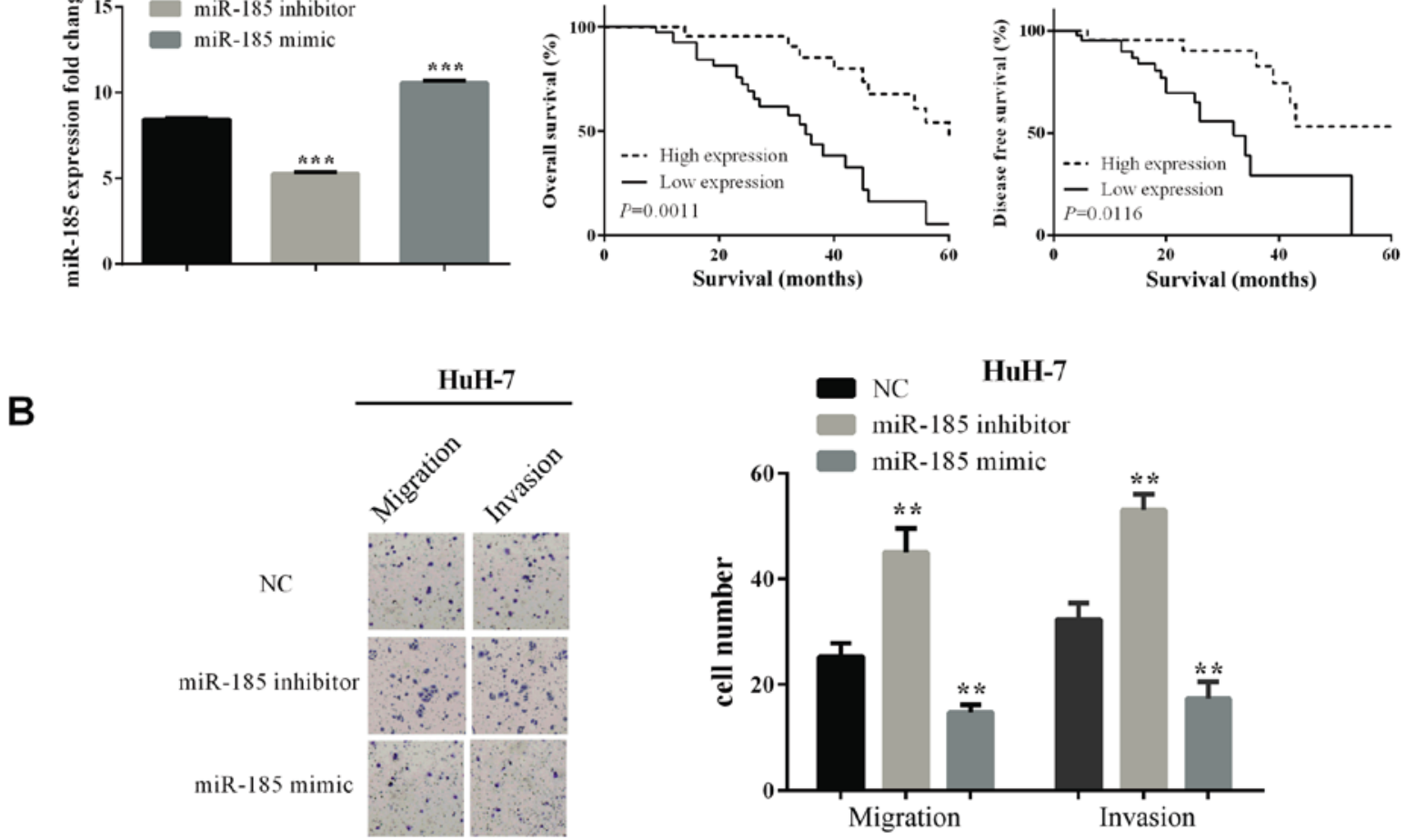

Figure 3. CDC42 is a target of miR-185 and mediated by miR-185. (A) The binding sites of CDC42 for miR-185 are located at 3'UTR. The mutated nucleotides are indicated overstriking, and named MUT. (B) Changes of luciferase activity when cells were co-transfected with miR-365 or negative control, and CDC42 3'UTR WT or MUT. (C) The mRNA and protein level of CDC42 when transfected with miR-185 mimic or miR-185 inhibitor in HuH-7 cells. ${ }^{* *} \mathrm{P}<0.01$; ${ }^{* * * *} \mathrm{P}<0.001$. CDC42, cell division cycle 42 .

of miR-185, the cells number that moved to the lower chamber was increased in HuH-7 (P-values for migration and invasion are 0.0029 and 0.0011 , respectively) cells, which illustrated the ability of migration and invasion to increase. On the contrary, in the overexpression of miR-185 inhibitor, the cell number was reduced in $\mathrm{HuH}-7$ ( $\mathrm{P}=0.0033$ and 0.0042 for migration and invasion) cells.

miR-185 was significantly related to tumor size $(\mathrm{P}=0.033)$, TNM stage $(\mathrm{P}=0.019)$, lymph node metastasis $(\mathrm{P}=0.023)$, as shown in Table I. OS and DFS of patients in miR-185(-) group was lower than that in miR-185(+) group (log-rank $\mathrm{P}=0.0011$ and 0.0116) based on Kaplan-Meier, as shown in Fig. 2C. The results revealed that miR-185 deficiency predicted poor prognosis in HCC.

miR-185 mediates the expression of CDC42 bydirect targeting. CDC42 was predicted to be a potential target by online software TargetScan (http://www.targetscan.org/vert_71/), which was reported to be related with tumor progression. The potential binding site of CDC42 for miR-185 is located at 647-654 at 3'UTR. Mutated the binding site from 5'-...UCUCUCC...-3' to $5 '$-...AGAGAGG...-3', as shown in Fig. 3A. To verify the association between CDC42 and miR-185, we co-transfected miR-185 or negative control and pcDNA3.1-CDC42-WT or pcDNA3.1-CDC42-MUT into HCC cells HuH-7. In co-transfection of miR-185 and pcDNA3.1-CDC42-WT, the relative luciferase activity was reduced compared with co-transfected negative control and pcDNA3.1-CDC42-WT
Table I. miR-185 expression and clinicopathological features in 63 paired $\mathrm{HCC}$.

\begin{tabular}{|c|c|c|c|c|}
\hline \multirow{2}{*}{$\begin{array}{l}\text { Clinicopathological } \\
\text { features }\end{array}$} & \multirow{2}{*}{$\begin{array}{l}\text { Cases } \\
(\mathrm{n}=63)\end{array}$} & \multicolumn{2}{|c|}{ miR-185 expression } & \multirow[b]{2}{*}{ P-value } \\
\hline & & High (\%) & Low $(\%)$ & \\
\hline Sex & & & & 0.782 \\
\hline Male & 30 & $11(36.7)$ & $19(63.3)$ & \\
\hline Female & 33 & $11(33.3)$ & $22(66.7)$ & \\
\hline Age (years) & & & & 0.679 \\
\hline$\leq 60$ & 28 & $9(32.1)$ & $19(67.9)$ & \\
\hline$>60$ & 35 & $13(37.1)$ & $22(62.9)$ & \\
\hline Tumor size (mm) & & & & $0.029^{\mathrm{a}}$ \\
\hline$\leq 5.0$ & 25 & $13(52.0)$ & $12(48.0)$ & \\
\hline$>5.0$ & 38 & $9(28.9)$ & $27(71.1)$ & \\
\hline TNM stage & & & & $0.035^{\mathrm{a}}$ \\
\hline I-II & 26 & $13(50.0)$ & $13(50.0)$ & \\
\hline III-IV & 37 & $9(24.3)$ & $28(75.7)$ & \\
\hline Local invasion & & & & 0.077 \\
\hline $\mathrm{T} 1-\mathrm{T} 2$ & 24 & $12(48.0)$ & $13(52.0)$ & \\
\hline T3-T4 & 39 & $10(26.3)$ & $28(73.7)$ & \\
\hline $\begin{array}{l}\text { Lymph node } \\
\text { metastasis }\end{array}$ & & & & $0.040^{\mathrm{a}}$ \\
\hline Positive & 33 & $8(24.2)$ & $26(75.8)$ & \\
\hline Negative & 30 & $14(46.7)$ & $15(53.3)$ & \\
\hline
\end{tabular}

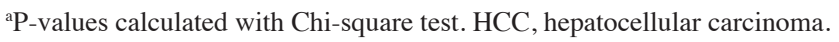


A

B

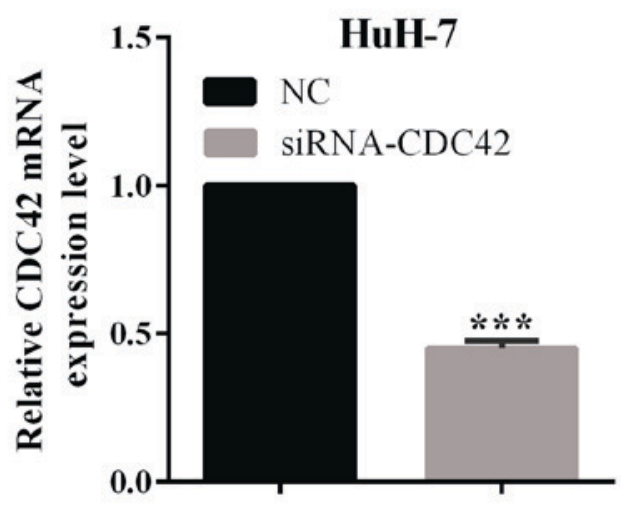

HuH-7

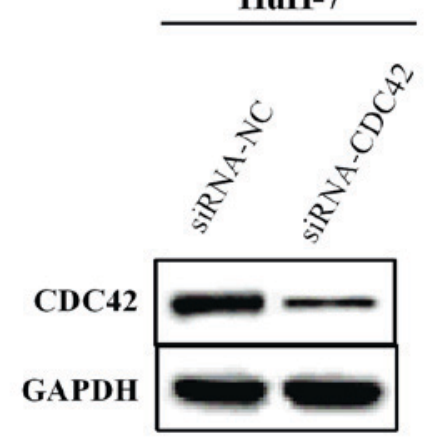

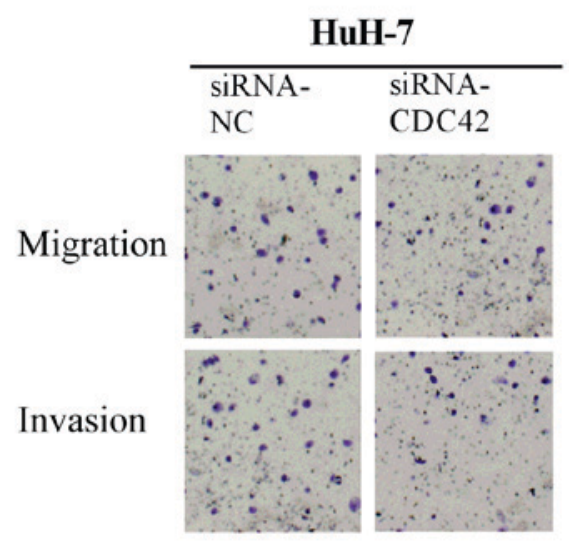

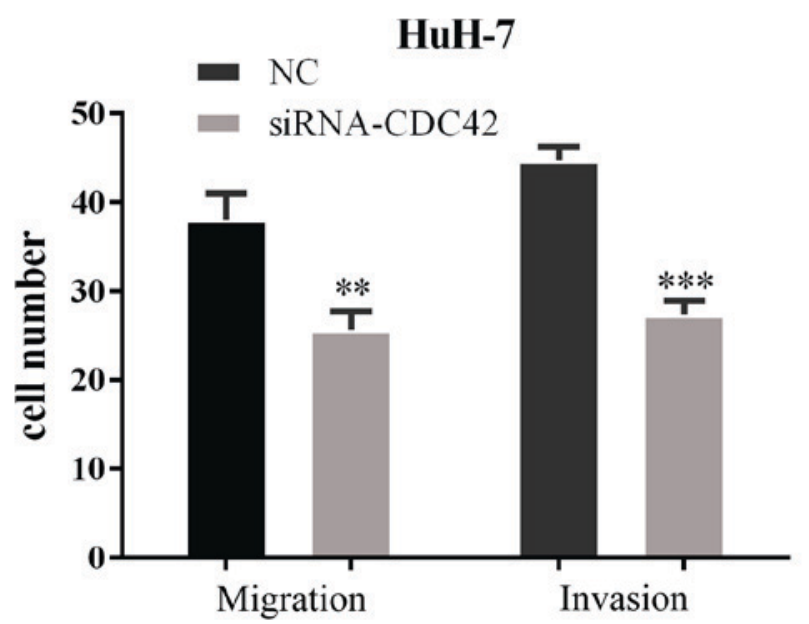

Figure 4. Interference of the expression of CDC42 reverses the partial function of miR-185. (A) RT-qPCR and western blotting displayed that mRNA and protein level of $\mathrm{CDC} 42$ reduced significantly after interference. (B) The ability of migration and invasion was reduced after interference with the expression of ADAM10. ${ }^{* *} \mathrm{P}<0.01 ;{ }^{* * * *} \mathrm{P}<0.001$. CDC42, cell division cycle 42 .

$(\mathrm{P}<0.0001$ of HuH-7). Whereas, co-transfected miR-185 and pcDNA3.1-CDC42-MUT had little change compared with $\mathrm{NC}$, and the P-value of HuH-7 was 0.8105 (Fig. 3B). The results show that miR-185 can directly bind to the $3^{\prime}$ UTR of CDC42. Previously it was shown that miR-185 can directly bind to the 3'UTR of CDC42, and the expression of miR-185 and CDC42 had a negative correlation. Therefore, we hypothesized that miR-185 could regulate the expression of CDC42. Unfortunately, in overexpressed or knocked down miR-185, the mRNA level of CDC42 had almost no change in either HuH-7 $(\mathrm{P}=0.074$ or 0.8190 for overexpression or knockdown miR-185) cells. On the contrary, the expression in protein level was reduced or increased significantly in $\mathrm{HuH}-7$ cells (Fig. 3C).

Interference of CDC42 partially blocks the function of $m i R-185$. To verify whether miR-185 affected cell migration and invasion by regulating CDC42 expression, we carried out a rescue experiment, which directly interfered with the expression of CDC42 to detect the ability of cell migration and invasion. The interference effect was measured by RT-qPCR $(\mathrm{P}<0.0001)$ and WB as shown in Fig. 4A. We calculated the cell number of migration and invasion by Transwell assay. The results showed that when interfered with $\mathrm{CDC} 42$, the cells number of migration and invasion was reduced in $\mathrm{HuH}-7$ $(\mathrm{P}=0.0043$ and 0.0002$)$ cells, which illustrated that the interfered CDC42 expression could reverse the partial function of miR-185.

\section{Discussion}

Primary liver cancer patients especially with $\mathrm{HCC}$ are prone to metastasis and recurrence. It has been reported that tumorigenesis was caused by oncogenes or loss of tumor inhibitors, whereas, several of the molecular biological mechanisms remain unknown (21). miRNAs are important epigenetic regulators and usually act as oncogene or tumor suppressor gene in progression of various cancers (22-28). miR-185 induces cell cycle arrest at the G1 phase to suppress proliferation in human non-small cell lung cancer cells (7). The expression of miR-185 in carcinoma was significantly lower than that in normal tissues, including $\mathrm{HCC}$, colon cancer and prostate carcinoma $(6,8,11)$. In this study, we discovered that miR-185 is usually drownregulated in $\mathrm{HCC}$ and the average expression level of miR-365 in tumor tissues was obviously lower than that in paracancerous tissues.

To ivestigate the role of miR-185, we overexpressed or knocked down miR-185 to detect the migration and invasion 
in HCC. It was found that the level of miR-185 was correlated with tumor migration and invasion. The ability of migration and invasion were reduced in transfection with miR-185 mimic, conversely, increased when the miR-185 inhibitor was transfected. Therefore, miR-185 mimics suppressed HCC cell migration and invasion, whereas, miR-215 inhibitor promoted cell migration and invasion.

miR-185 expression was negative correlated with lymph node metastasis and low expression of miR-185 is associated with poor prognosis in colon cancer and glioma patients (29). miR-185 was found to inhibit cell invasion, which indicated that it may be a potential prognostic marker in glioma (29). Previous studies have revealed that miR-185 impedes cell migration and invasion, suppressed tumor growth and increasing cisplatin sensitivity by facilitating apoptosis, indicating it as a tumor inhibiting factor $(8,30,31)$. In our study, we divided 63 patients into high expression group and low expression group according to RNA levels, and we found that the prognosis of high expression group was better.

In human colorectal cells miR-185 suppressed cell proliferation through inhibiting CDC42 in transcription level (11). In our study, we first confirmed CDC42 was a direct target of miR-185 in HCC by RT-qPCR. Furthermore, miR-185 was negatively correlated with $\mathrm{CDC} 42$, which was highly expressed in carcinomatous tissues $(32,33)$.

CDC42 is regulated by several miRNAs and genes in HCC. For example, miR-137 was reported to inhibit cell proliferation and metastasis by regulating CDC42 in HCC (13). In esophageal squamous cell carcinoma, miR-107 targeting CDC42 suppress proliferation, migration and invasion (33). Furthermore, Zhang et al (34) and $\mathrm{Xu}$ et al (32) found that Bif-1 (endophilin B1 or SH3GLB1) and HBx (Hepatitis B Virus $\mathrm{X}$ Protein) promotes HCC cell proliferation, migration and inhibits apoptosis via CDC42 expression and activity. To identify whether CDC42 is a direct target of miR-365, we mutated the binding site of CDC42 3'UTR and performed the luciferase reporter assay. Trough luciferase reporter assay, we confirmed that CDC42 was a direct target of miR-185, which was the first time to propose that miR-185 targeted CDC42 in HCC. In addition, Liu et al suggested that miR-185 targeted CDC42 and inhibited cell proliferation in colorectal cells (11). Consistent with these findings, in this study we found that CDC42 protein expression was mediated by miR-185 and changed along with miR-185 in protein level, whereas miR-185 did not alter the CDC42 mRNA level.

Furthermore, in order to confirm the biological role of $\mathrm{CDC} 42$ in HCC, recovery experiment was carried out and it was found that interference of CDC42 inhibited the migration and invasion of HCC cells. Additionally, we found that depletion of CDC42 reversed partial the function of miR-185.

In conclusion, our results suggest that miR-185 is usually expressed at low level in HCC. Moreover, interference of miR-185 promotes the ability of migration and invasion of HCC cells by directly targeting CDC42. Thus, our findings displayed that miR-185 may be developed to a potential diagnostic marker of HCC. miR-185 was expressed at low level in HCC tissues and cell lines indicating poor prognosis. miR-185 inhibited the ability of migration and invasion through downregulation of the expression level of CDC42 by direct targeting.

\section{Acknowledgements}

Not applicable.

\section{Funding}

No funding was received.

\section{Availability of data and materials}

The datasets used and/or analyzed during the current study are available from the corresponding author on reasonable request.

\section{Authors' contributions}

QZ contributed to the conception of the study and wrote the manuscript. YC contributed significantly to perform the experiment. KL contributed significantly to the analysis of the data and helped in the writing of the manuscript. All authors have read and approved the final manuscript.

\section{Ethics approval and consent to participate}

This study was approved by the Ethics Committee of Central Hospital of Zibo (Zibo, China) and informed consent of each patient was received.

\section{Patient consent for publication}

Not applicable.

\section{Competing interests}

The authors declare that they have no competing interests.

\section{References}

1. El-Serag HB and Rudolph KL: Hepatocellular carcinoma: Epidemiology and molecular carcinogenesis. Gastroenterology 132: 2557-2576, 2007.

2. Lauressergues D, Couzigou JM, Clemente HS, Martinez Y, Dunand C, Becard G and Combier JP: Primary transcripts of microRNAs encode regulatory peptides. Nature 520: 90-93, 2015.

3. Voinnet O: Origin, biogenesis, and activity of plant microRNAs. Cell 136: 669-687, 2009.

4. Di Giacomo G, Koss M, Capellini TD, Brendolan A, Popperl H and Selleri L: Spatio-temporal expression of $\mathrm{Pbx} 3$ during mouse organogenesis. Gene Expr Patterns 6: 747-757, 2006.

5. Lichtenauer UD, Duchniewicz M, Kolanczyk M, Hoeflich A, Hahner S, Else T, Bicknell AB, Zemojtel T, Stallings NR, Schulte DM, et al: Pre-B-cell transcription factor 1 and steroidogenic factor 1 synergistically regulate adrenocortical growth and steroidogenesis. Endocrinology 148: 693-704, 2007.

6. Liu C, Chen Z, Hu X, Wang L, Li C, Xue J, Zhang P, Chen W and Jiang A: MicroRNA-185 downregulates androgen receptor expression in the LNCaP prostate carcinoma cell line. Mol Med Rep 11: 4625-4632, 2015.

7. Takahashi Y, Forrest AR, Maeno E, Hashimoto T, Daub CO and Yasuda J: miR-107 and miR-185 can induce cell cycle arrest in human non small cell lung cancer cell lines. PLoS One 18: e6677, 2009.

8. Imam JS, Buddavarapu K, Lee-Chang JS, Ganapathy S, Camosy C, Chen Y and Rao MK: MicroRNA-185 suppresses tumor growth and progression by targeting the Six 1 oncogene in human cancers. Oncogene 29: 4971-4979, 2010. 
9. Akçakaya P, Ekelund S, Kolosenko I, Caramuta S, Ozata DM, Xie $\mathrm{H}$, Lindforss U, Olivecrona $\mathrm{H}$ and Lui WO: miR-185 and miR-133b deregulation is associated with overall survival and metastasis in colorectal cancer. Int J Oncol 39: 311-318, 2011.

10. Lu ZJ, Lu LG, Tao KZ, Chen DF, Xia Q, Weng JJ, Zhu F, Wang XP and Zheng P: MicroRNA-185 suppresses growth and invasion of colon cancer cells through inhibition of the hypoxiainducible factor-2alpha pathway in vitro and in vivo. Mol Med Rep 10: 2401-2408, 2014

11. Liu M, Lang N, Chen X, Tang Q, Liu S, Huang J, Zheng Y and Bi F: miR-185 targets RhoA and Cdc42 expression and inhibits the proliferation potential of human colorectal cells. Cancer Lett 301: 151-160, 2011

12. Zhu X, Li Y, Shen H, Li H, Long L, Hui L and Xu W: miR-137 inhibits the proliferation of lung cancer cells by targeting Cdc42 and Cdk6. FEBS Lett 587: 73-81, 2013.

13. Liu M, Lang N, Qiu M, Xu F, Li Q, Tang Q, Chen J, Chen X, Zhang S, Liu Z, et al: miR-137 targets Cdc42 expression, induces cell cycle G1 arrest and inhibits invasion in colorectal cancer cells. Int J Cancer 128: 1269-1279, 2011.

14. Fritz G, Just I and Kaina B: Rho GTPases are over-expressed in human tumors. Int J Cancer 81: 682-687, 1999.

15. Zegers MM and Friedl P: Rho GTPases in collective cell migration. Small GTPases 5: e28997, 2014.

16. Arias-Romero LE and Chernoff J: Targeting Cdc42 in cancer. Expert Opin Ther Targets 17: 1263-1273, 2013.

17. Stengel K and Zheng Y: Cdc42 in oncogenic transformation, invasion, and tumorigenesis. Cell Signal 23: 1415-1423, 2011.

18. Yang L, Wang L and Zheng Y: Gene targeting of Cdc42 and Cdc42GAP affirms the critical involvement of Cdc42 in filopodia induction, directed migration, and proliferation in primary mouse embryonic fibroblasts. Mol Biol Cell 17: 4675-4685, 2006

19. Chang CS, Huang SM, Lin HH, Wu CC and Wang CJ: Different expression of apoptotic proteins between HBV-infected and non-HBV-infected hepatocellular carcinoma. Hepatogastroenterology 54: 2061-2068, 2007.

20. Cooper AB, Wu J, Lu D and Maluccio MA: Is autotaxin (ENPP2) the link between hepatitis $\mathrm{C}$ and hepatocellular cancer? J Gastrointest Surg 11: 1628-1634, 2007.

21. Porta C, Larghi P, Rimoldi M, Totaro MG, Allavena P, Mantovani A and Sica A: Cellular and molecular pathways linking inflammation and cancer. Immunobiology 214: 761-777, 2009.

22. Lu J, Getz G, Miska EA, Alvarez-Saavedra E, Lamb J, Peck D, Sweet-Cordero A, Ebert BL, Mak RH, Ferrando AA, et al: MicroRNA expression profiles classify human cancers. Nature 435: 834-838, 2005.

23. Iorio MV and Croce CM: MicroRNAs in cancer: Small molecules with a huge impact. J Clin Oncol 27: 5848-5856, 2009.
24. Jiang C, Chen X, Alattar M, Wei J and Liu H: MicroRNAs in tumorigenesis, metastasis, diagnosis and prognosis of gastric cancer. Cancer Gene Ther 22: 291-301, 2015.

25. Duan J, Zhang H, Qu Y, Deng T, Huang D, Liu R, Zhang L, Bai M, Zhou L, Ying G, et al: Onco-miR-130 promotes cell proliferation and migration by targeting TGFbetaR2 in gastric cancer. Oncotarget 7: 44522-44533, 2016.

26. Fabbri M, Garzon R, Cimmino A, Liu Z, Zanesi N, Callegari E, Liu S, Alder H, Costinean S, Fernandez-Cymering C, et al: MicroRNA-29 family reverts aberrant methylation in lung cancer by targeting DNA methyltransferases 3A and 3B. Proc Natl Acad Sci USA 104: 15805-15810, 2007.

27. He L, Thomson JM, Hemann MT, Hernando-Monge E, Mu D, Goodson S, Powers S, Cordon-Cardo C, Lowe SW, Hannon GJ, et al: A microRNA polycistron as a potential human oncogene. Nature 435: 828-833, 2005.

28. Esquela-Kerscher A and Slack FJ: Oncomirs-microRNAs with a role in cancer. Nat Rev Cancer 6: 259-269, 2006.

29. Tang H, Wang Z, Liu X, Liu Q, Xu G, Li G and Wu M: LRRC4 inhibits glioma cell growth and invasion through a miR-185-dependent pathway. Curr Cancer Drug Targets 12: 1032-1042, 2012.

30. Xiang Y, Ma N, Wang D, Zhang Y, Zhou J, Wu G, Zhao R, Huang $\mathrm{H}$, Wang $\mathrm{X}$, Qiao $\mathrm{Y}$, et al: miR-152 and miR-185 co-contribute to ovarian cancer cells cisplatin sensitivity by targeting DNMT1 directly: a novel epigenetic therapy independent of decitabine. Oncogene 33: 378-386, 2014.

31. Li S, Ma Y, Hou X, Liu Y, Li K, Xu S and Wang J: miR-185 acts as a tumor suppressor by targeting AKT1 in non-small cell lung cancer cells. Int J Clin Exp Pathol 8: 11854-11862, 2015.

32. Xu Y, Qi Y, Luo J, Yang J, Xie Q, Deng C, Su N, Wei W, Shi D, $\mathrm{Xu}$ F, et al: Hepatitis B virus $\mathrm{X}$ protein stimulates proliferation, wound closure and inhibits apoptosis of $\mathrm{HuH}-7$ cells via $\mathrm{CDC} 42$. Int J Mol Sci 18: e586, 2017.

33. Sharma P, Saini N and Sharma R: miR-107 functions as a tumor suppressor in human esophageal squamous cell carcinoma and targets Cdc42. Oncol Rep 37: 3116-3127, 2017.

34. Zhang C, Liu F, Chen H, Li N, Luo Z, Guo W, Huang D, Tang S, Wang $\mathrm{H}$, Cheng S, et al: Bif-1 promotes tumor cell migration and metastasis via Cdc42 expression and activity. Clin Exp Metastasis 34: 11-23, 2017.

This work is licensed under a Creative Commons

Attribution-NonCommercial-NoDerivatives 4.0 International (CC BY-NC-ND 4.0) License. 